\title{
PRÁTICA PEDAGÓGICA NO CONTEXTO DE PIANO EM GRUPO: HARMONIZANDO A MÚSICA BOOGIE BLUES
}

\section{PEDAGOGICAL PRACTICE IN GROUP PIANO SETTINGS: HARMONIZING THE THEME BOOGIE BLUES}

\author{
Liliana Harb Bollos \\ Universidade Federal de Goiás \\ contato@lilianabollos.com.br \\ Carlos Henrique Costa \\ Universidade Federal de Goiás \\ costacarlosh@yahoo.com.br
}

\section{Resumo}

Este artigo discute a Harmonização como ferramenta imprescindivel da formação pianística e parte integrante da disciplina Piano Complementar nos cursos de Licenciaturas em Música e aponta procedimentos pedagógicos embasados no estudo harmônico do piano popular. Nosso objetivo é apontar aspectos do processo de aprendizagem cognitiva e motora dos alunos no contexto de aulas coletivas de piano diante da aplicação de uma prática pedagógica específica de harmonização de uma melodia. Ao analisar o que se pratica, adquire-se habilidade para se entender seu caminho harmônico, capacitando também a memorização e a transposição. Também apresenta diversas etapas de execução na música "Boogie blues", com baixo, acorde, melodia e improvisação e os resultados obtidos dessa experiência realizada dentro da pesquisa-ação em três classes e duas instituições de ensino superior.

Palavras-chave: harmonização; piano em grupo; piano complementar; blues. 


\begin{abstract}
This article discusses the harmonization as a vital tool of Piano formation and an integral part of Class Piano in Undergraduate Music courses and it points out pedagogical procedures based on the harmonic study of popular piano. Our purpose is to point out aspects of cognitive and motor learning processes of students in the context of group piano lessons exposed to a specific pedagogical practice of harmonizing a melody. By analyzing what is practiced, skill is acquired to understand his harmonic way, also enabling the memorization and the transposition. Also presents several steps of execution in the music "Boogie Blues" with bass, chord, melody, improvisation and the results of this experiment within action research conducted in three classes and two higher education institutions.
\end{abstract} blues.

Keywords: harmonization; group piano; supplementary piano;

\title{
Lista de figuras
}

Figura 1: "Boogie blues".

Figura 2: "Boogie blues" com baixo ostinato.

Figura 3: acompanhamento na mão direita.

Figura 4: "Boogie blues" com três pentagramas.

Figura 5: "Boogie blues" com acorde e melodia na mão direita.

Figura 6: "Boogie blues" com melodia e acorde em cada tempo na mão direita.

Figura 7: improvisação na forma Blues em Sol.

Figura 8: Questionário Boogie Blues.

Fonte: arquivo do autor. 


\section{Introdução}

A disciplina Piano Complementar é parte integrante dos currículos de cursos de graduação em licenciaturas e bacharelados por todo o país de forma muito híbrida, com muitas diferenças entre os repertórios trabalhados e os objetivos almejados de cada curso. A carga horária pode variar de dois a quatro semestres para disciplinas que envolvem o ensino coletivo de piano (digital ou teclado), com grande diversidade de repertório, número de alunos e até mesmo o nome da disciplina, podendo ser encontrada como Piano Complementar, Piano em Grupo, Teclado, Piano Suplementar, Prática Instrumental Pedagógica, Piano Funcional, Piano Instrumental, Harmonia no Teclado, entre outros.

Diante da heterogeneidade dos alunos, o repertório trabalhado nas aulas de Piano complementar deve ser cuidadosamente escolhido, pois, além do repertório tradicional erudito amplamente disseminado pelos conservatórios e escolas de música há décadas, há uma crescente procura por parte de alunos nos cursos de Licenciatura em Música para entrar em contato com o universo popular e estudar seu repertório, por sua utilidade nos espaços de trabalho e pela riqueza harmônica como material de ensino-aprendizagem, uma vez que em sala de aula, nos anos iniciais, ensino fundamental ou médio, o repertório popular é muito presente. Não basta incluir partituras escritas do cancioneiro popular no repertório mas desenvolver habilidades para que os alunos aprendam a harmonizar e criar arranjos. Desse modo, além de se trabalhar fundamentos como técnica e desenvolvimento de repertório, a ferramenta fundamental para o desenvolvimento do ensino do piano popular, e para qualquer instrumento harmonizador, é o estudo da harmonia aplicada ao instrumento.

Diante do exposto questiona-se como pode-se apresentar um conteúdo que será útil e altamente relevante para os alunos e não somente para os propósitos pedagógicos? Como pode-se dar o estudo consciente da harmonia dentro da prática instrumental pianística em grupo, aproximando teoria e prática? $\bigcirc$ músico, ao analisar e conhecer melhor os caminhos harmônicos da música estudada, irá compreender e assimilar mais assertivamente a música estudada, de modo que terá mais exito tanto para compreender e executar quanto para harmonizar, memorizar e transpor suas peças conscientemente. 
Este artigo discute a Harmonização como ferramenta essencial e parte integrante da disciplina Piano Complementar nos cursos de Licenciaturas em Música, aproximando a prática instrumental ao ensino da harmonia e propõe uma sequência prática de conceitos com atividades para a execução da peça "Boogie Blues" assim como os resultados obtidos através da aplicação dos modelos propostos dentro de experiências de ensino em duas instituições de nível superior, na Universidade Federal de Goiás e na Faculdade Campo Limpo Paulista e é parte da pesquisa de Pós-doutorado junto à Escola de Música e Artes Cênicas da Universidade Federal de Coiás. A linha de pesquisa se apoia na pesquisa-ação, de base empírica, de modo participativo, com o objetivo de refletir e intervir criticamente sobre nossos procedimentos pedagógicos, construindo, assim, novos saberes. Os instrumentos de coleta de dados desta pesquisa se basearam em questionários escritos, observações práticas das aulas e registros audiovisuais desses eventos e a ferramenta de coleta de dados foi a observação participante, que serviu para compreender e esclarecer dúvidas a respeito dos processos de ensino e aprendizagem dos alunos. As discussões são norteadas por parâmetros que envolvem os processos cognitivo e motor, quais sejam: compreensão do estilo (forma blues, a relação dos acordes, a execução de tercinas) e a movimentação ao piano (encadeamento de acordes, dedilhado, saltos) advindos das propostas pedagógicas aplicadas.

\section{Especificidades do Piano em grupo}

Oensino do formato piano em grupo tem sido tópico de discussão e pesquisa pelo seu potencial metodológico tanto na qualidade de ensino quanto no número de alunos envolvidos no processo ensinoaprendizagem. Funciona como uma ferramenta que aplica conceitos de teoria musical e análise harmônica à prática do instrumento podendo resultar em ensino eficiente. Ademais, a característica principal do ensino coletivo, qual seja, a interação e compartilhamento de conhecimentos e experiências entre o grupo demonstra um potencial que deve ser entendido e pesquisado haja vista o caráter disciplinar em que as universidades e consequentemente todos os níveis de ensino contemporâneo estão inseridos. 
Ao longo do século XX, motivados pela necessidade de justificarem suas funções perante a sociedade norte-americana, diversos pesquisadores propuseram reformas relacionadas ao ensino da música, dentro e fora da escola pública, reforçando seu vínculo com o ensino da linguagem musical e não somente como adestramento da execução no instrumento (MONTANDON, 1992, p. 1). Diante do interesse de professores e pesquisadores da área como Robert Pace, Lovise Bianchi, James Lyke e James Bastien, entre outros, universidades americanas implantaram laboratórios de piano em grupo e capacitaram profissionais para atuação na área desde 1960, resultando na fomentação de festivais, convenções e workshops na área. Desde então, a metodologia de ensino do piano em grupo tem sido tópico de livros, artigos e teses nos Estados Unidos. Alguns dos métodos americanos resultantes desses encontros e pesquisas são "Alfred's Group Piano for Adults" de E. L. Lancaster e Kenon D. Renfrow, "Class Piano Resource Materials" de W. Daniel Landes, "Music for piano" de Robert Pace, entre outros.

A introdução do ensino de piano em grupo (EPG) no Brasil ocorreu em 1976 quando a professora Abigail Rodrigues Silva, então diretora do Programa Robert Pace no Brasil ofereceu em São Paulo um curso sobre esse método, no qual inscreveu-se a professora Maria José Michalski que levou o formato de EPC para a Escola de Música Villa-Lobos. Lá trabalhava a professora Maria de Lourdes Junqueira Gonçalves, docente na Universidade Federal do Rio de Janeiro, que, após receber aprovação para sua pesquisa sobre o Ensino de Piano em Grupo e participar do Encontro de Pace em 1977, recebeu bolsa da Fulbright para dar continuidade às suas pesquisas nos EUA em meados de 1978. Lá estudou com importantes professores e, retornado ao Brasil, montou o primeiro curso de Pós-graduação em Ensino do Piano em Grupo e criou em parceria com Cacilda Borges Barbosa uma coleção de livros didáticos intitulados EMAT (Educação Musical Através do Teclado), cuja utilização dessa metodologia de ensino e criação de métodos tem sido direcionada principalmente para crianças e iniciantes (Machado, 2016, p. 139; Montandon, 1992, p. 1 | 1-1 16; Reinoso, 2012, p. 61-64).

Entretanto, o cenário atual no Brasil demonstra que outros músicos-professores de piano, por ocasião de suas qualificações em universidades americanas, foram apresentados às metodologias de ensino de piano em grupo, o que tem resultado em vários focos de ensino e pesquisa no país. Nas últimas duas décadas alguns dos programas de 
piano em grupo para universitários no Brasil tem estado sob orientação dos professores Diana Santiago e Eduardo Conde Carcia (Universidade Federal da Bahia), Isabel Montandon (Universidade de Brasília), Helena Puglia Freire (Universidade Federal de Minas Gerais), Fátima Corvisier e Simone Gorete Machado (Universidade de São Paulo campus Ribeirão Preto), Carlos Henrique Costa (Universidade Federal de Coiás) e Rosane Cardoso de Araújo e Zélia Chueke (Universidade Federal do Paraná), entre outros pesquisadores. Alguns desses focos de ensino são frutos de estudos e experiências de professores supra citados que fizeram mestrado ou doutorado nos Estados Unidos, onde laboratórios de piano em grupo existem em quase todas as universidades desde os anos 1980.

$\bigcirc$ ensino de piano em grupo requer metodologias específicas com material adequado. Em nível universitário, há o desafio de equipar os estudantes de música, sejam eles regentes, professores de instrumento, compositores, arranjadores ou educadores musicais, com a proficiência necessária com habilidades básicas tais como leitura à primeira vista, acompanhamento, transposição, improvisação e harmonização. Desse modo, a disciplina em questão, doravante chamada Piano Complementar (por se tratar da nomenclatura utilizada no contexto da pesquisa) ministrada em grupo, proporciona a utilização do piano como instrumento funcional com o objetivo de desenvolver múltiplas habilidades. Nos E.U.A., há um número expressivo de autores que escreveram para esse contexto como Lancaster e Renfrow (1996), Alexander et al (2003), Hilley \& Freeman (2001), Coats (2006), Lyke \& Yvonne (1987), Fisher (2010) e Bastien (1973), entre outros. No Brasil, há relatos de várias pesquisas destacando o desenvolvimento de repertório como Couto (2008), Lucca (2005), Melo (2002) e Santos (2013) e um método publicado, o livro Piano em grupo: livro didático para o ensino superior (Ed. PUC-Coiás, 2012) de Carlos Costa e Simone Gorete Machado. $O$ interesse por estratégias didáticas para ensino coletivo de piano tem aumentado nas últimas décadas e há uma necessidade iminente de se discutir não só as especificidades do formato Piano em grupo, mas de se conhecer e sobretudo apresentar os procedimentos pedagógicos, materiais utilizados e repertórios desenvolvidos nesses grupos. 


\section{A Harmonização no ensino instrumental}

Podemos conceituar a harmonia como o campo que estuda as relações de encadeamentos de sons simultâneos. Assim, a harmonia se articula com a organização interna do sistema tonal, que estrutura uma série específica de acordes que formam o denominado campo harmônico. Harmonização, por outro lado, é o ato de executar a harmonia, aplicar a harmonia dentro do repertório musical, a partir de uma melodia. Carlos Almada (2009) afirma que a harmonia representa o núcleo da formação consistente de um músico:

A Harmonia não se deve limitar a uma simples catalogação de acordes ou a uma série de informações impostas, desconexas entre si, ou de "macetes" com finalidades imediatas e superficiais. É reduzir e banalizar algo tão importante. Não são todos os que realmente se dão conta de que estudar Harmonia significa algo muitíssimo mais profundo: é conhecer a própria matéria da Música. Compreender os complexos laços funcionais que ligam hierarquicamente as notas de uma tonalidade e, consequentemente, a rede de acordes por elas gerada. Observar a organização tonal e descobrir que o sistema harmônico como um todo é deduzido inteiramente de suas premissas (Almada, 2009, p. 11).

Aprender a harmonizar ao piano envolve entender, processar e reconhecer espacialmente esses complexos laços funcionais a partir de uma melodia, identificando a espacialidade das vozes e suas funções harmônicas, um processo cognitivo e o estudo dos processos cognitivos presentes no fazer musical nos permite não somente compreender melhor este fazer: pode contribuir também para a melhoria da qualidade dos processos de ensino e aprendizagem. (Santiago; Fonseca; 2013, p. 1 16). Além do fator cognitivo, no estudo instrumental há de se levar em conta o aspecto motor, a habilidade técnica ao piano, pois desenvolver as formas dos acordes e a habilidade de mudar de um acorde para outro abrange destreza motora, mas também possibilita reconhecer 'formatos' de acordes e cadências que se repetem em todas as tonalidades, o que na verdade também possibilita a prática da transposição mais facilmente. Escolhemos, portanto, para os objetivos desta pesquisa, dois 
indicadores: o conhecimento do estilo (cognitivo) e a movimentação ao piano (motor).

Dessa forma, com relação ao processamento de conhecimento harmônico podemos afirmar que fundamentos como harmonização, transposição, improvisação e acompanhamento estão interligados e podem assim como devem ser desenvolvidos na disciplina Piano Complementar. Maria Inêz Machado pontua ser imprescindível a experiência com o piano na formação de um aluno da Licenciatura:

A desenvoltura na percepção harmônica é um suporte fundamental para a qualidade do trabalho de um musicalizador, seja na escola especializada, ou da rede regular de ensino, seja em aulas particulares. 0 potencial expressivo do futuro educador musical pode ser explorado - e valorizado - através do tratamento consciente de possibilidades dinâmicas e timbrísticas do piano (ou teclado com sensibilidade ao toque). Deste profissional são esperadas, dentre outras, as capacidades de fazer harmonizações, pequenos arranjos, transposições, improvisações. Presumimos ser interessante a habilidade específica no piano porque, mesmo não sendo um instrumento comumente disponivel nas escolas regulares, há como se utilizar um teclado nas aulas, com vantagens de um instrumento harmônico que permite aos alunos a visualização e a experimentação da organização das alturas e de pequenas estruturas musicais (Machado, 2013, p. 122-123).

A atividade descrita a seguir foi formulada para ser trabalhada no formato piano em grupo, com alunos de diversas experiências musicais, tanto de ponto de vista instrumental quanto teórico, logo, ressaltase que tocar em grupo significa trocar, transformar conhecimentos, perceber e vivenciar a pulsação da música e a de seus colegas. Segundo Keith Swanwick, o trabalho em grupo é uma excelente forma de enriquecer e ampliar o ensino de um instrumento e a aprendizagem em música envolve imitação e comparação com outras pessoas. Segundo ele, somos fortemente motivados ao observar os outros e tendemos a competir com nossos colegas, o que tem um efeito mais direto do que 
quando instruídos apenas por aquelas pessoas as quais chamamos 'professores' (Swanwick, 1994, p. 9-10).

Nesse sentido, nosso objetivo é propor uma prática em grupo voltada para o desenvolvimento instrumental mas também ao aspecto harmônico, para que os alunos tenham mais entendimento da harmonia, facilitando outras habilidades como improvisação, transposição e memorização de partituras e de progressões harmônicas. José Alberto Kaplan pontua que a compreensão irá facilitar a fixação e posteriormente a assimilação do conhecimento e a memória, cooperando ainda para que o músico toque sem se prender à partitura e controle melhor auditivamente o que se está executando. Em suma, quando tratamos da importância da repetição na aquisição das habilidades motoras necessárias para atender às exigências musicais da partitura, "a fiscalização auditiva é uma das peças chaves do processo de aprendizagem músico-instrumental" (Kaplan, 1987, p. 83). Ele afirma ainda que o grau de dificuldade de execução de uma determinada habilidade ou destreza não se encontra nela mesma e sim na capacidade de realização do indivíduo que a executa, o que interfere sobremaneira na performance.

\section{Harmonização em "Boogie blues"}

Neste momento descreveremos a atividade com a música "Boogie blues" (Liliana Bollos) e exemplificaremos as várias possibilidades rítmicoharmônicas que foram trabalhadas com este blues, fazendo com que alunos de diferentes habilidades e vivências pudessem executar os arranjos progressivamente. A primeira atividade trabalhada foi a leitura à primeira vista, solfejando, cantando a melodia. A leitura à segunda vista, então, foi feita e os alunos foram encorajados a conduzir a leitura em tempo lento proposto pelo professor até o final, com uma mão ou simultaneamente, para os alunos mais experientes. Estamos diante de uma forma blues tradicional de doze compassos, | I | I | I I I IV | IV | I I I $\mathrm{V}|\mathrm{IV}| \mathrm{I}|\mathrm{I}|$ : 

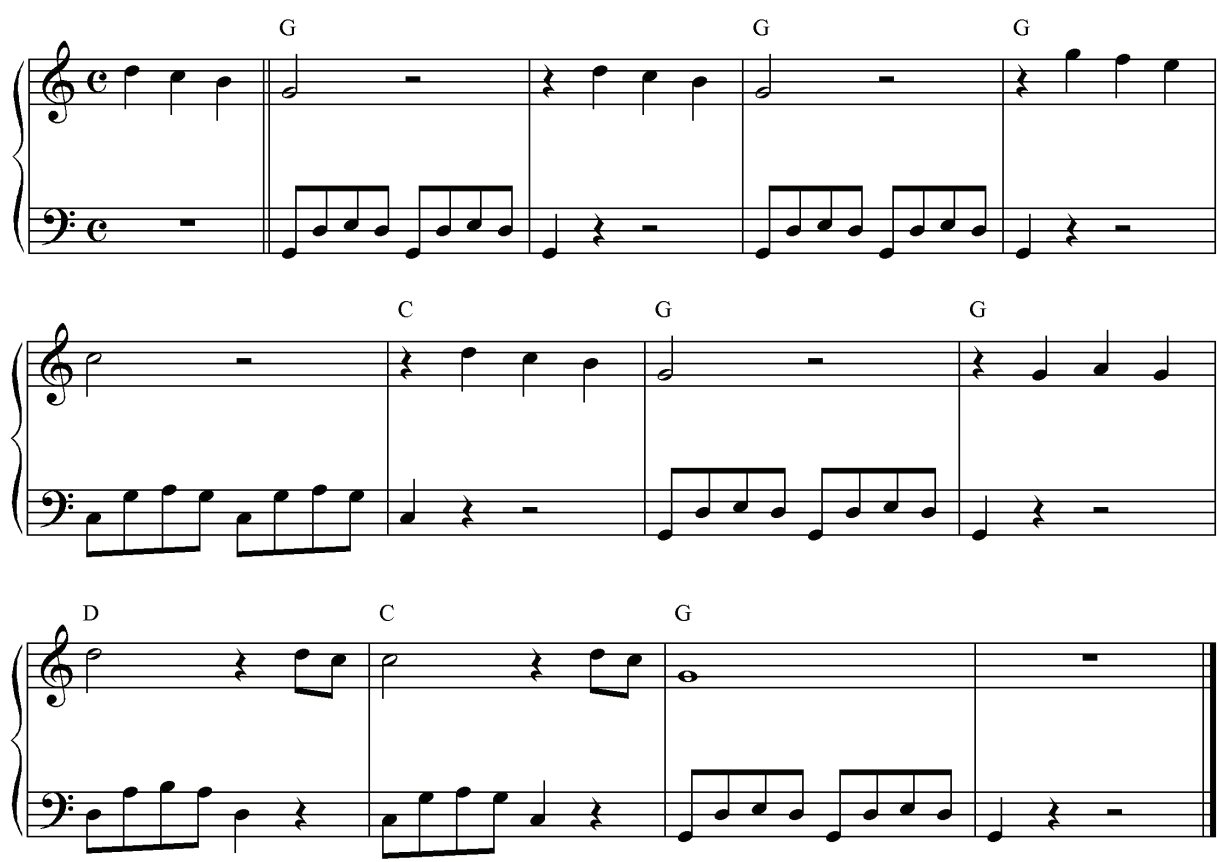

Figura I: "Boogie blues".

Os alunos executaram o tema (figura 1) sem muita dificuldade, entretanto somente alunos com experiência tocaram de imediato o tema com mãos simultâneas. Fizemos a análise melódica e identificamos as tríades na melodia, de modo que os alunos puderam perceber que a harmonia também estava na melodia arpejada. A partir dessa análise uma nova opção de baixo foi proposta oralmente, o baixo ostinato, uma espécie de figuração executada continuamente no estilo boogie woogie em que a mão esquerda executa de forma constante e ininterrupta o mesmo padrão. Com o baixo ostinato, "Boogie blues" foi interpretada da seguinte forma: 

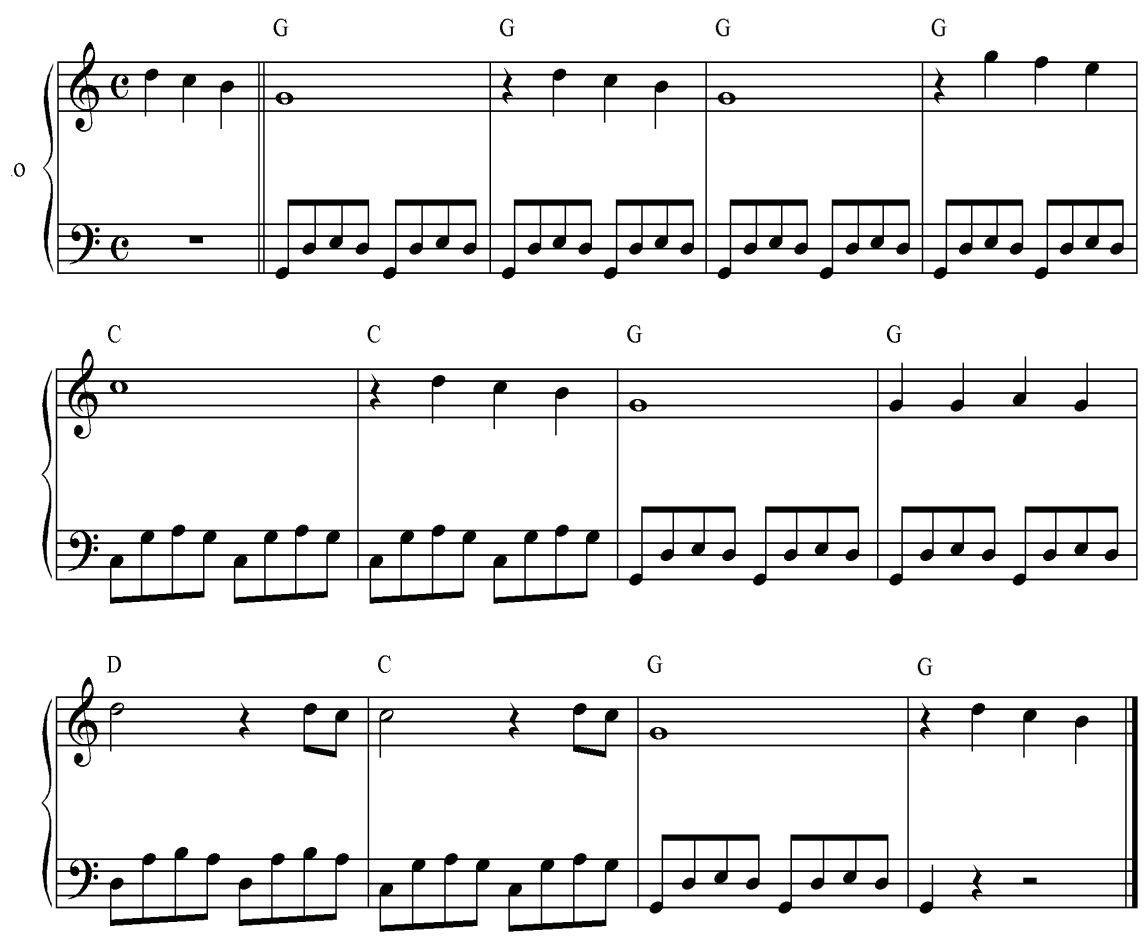

Figura 2: "Boogie blues" com baixo ostinato.

A próxima atividade foi sistematizar os acordes conforme a forma do blues, escolhendo para a mão direita o acorde Sol na primeira inversão e os acordes Dó e Ré na posição fundamental, a fim de deslocar o mínimo possível os próximos acordes, encadeando-os:

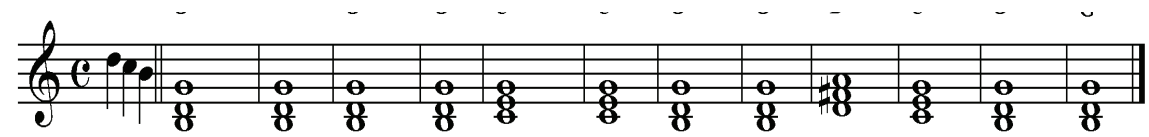

Figura 3: acordes na mão direita.

Nessa etapa propusemos o acompanhamento em tríades com 
ambas as mãos separadamente partindo das três posições, fundamental, primeira inversão (figura 3) e segunda inversão, a fim de fortalecer a harmonização e escolha de acordes.

Uma próxima etapa foi introduzir uma nova harmonização para o acompanhamento de acordes em terças utilizando uma partitura com três pentagramas (figura 4) para melodia, acompanhamento e baixo ostinato. Com ela os alunos visualizam as três opções, podendo praticar também o exercício com ambas as mãos.
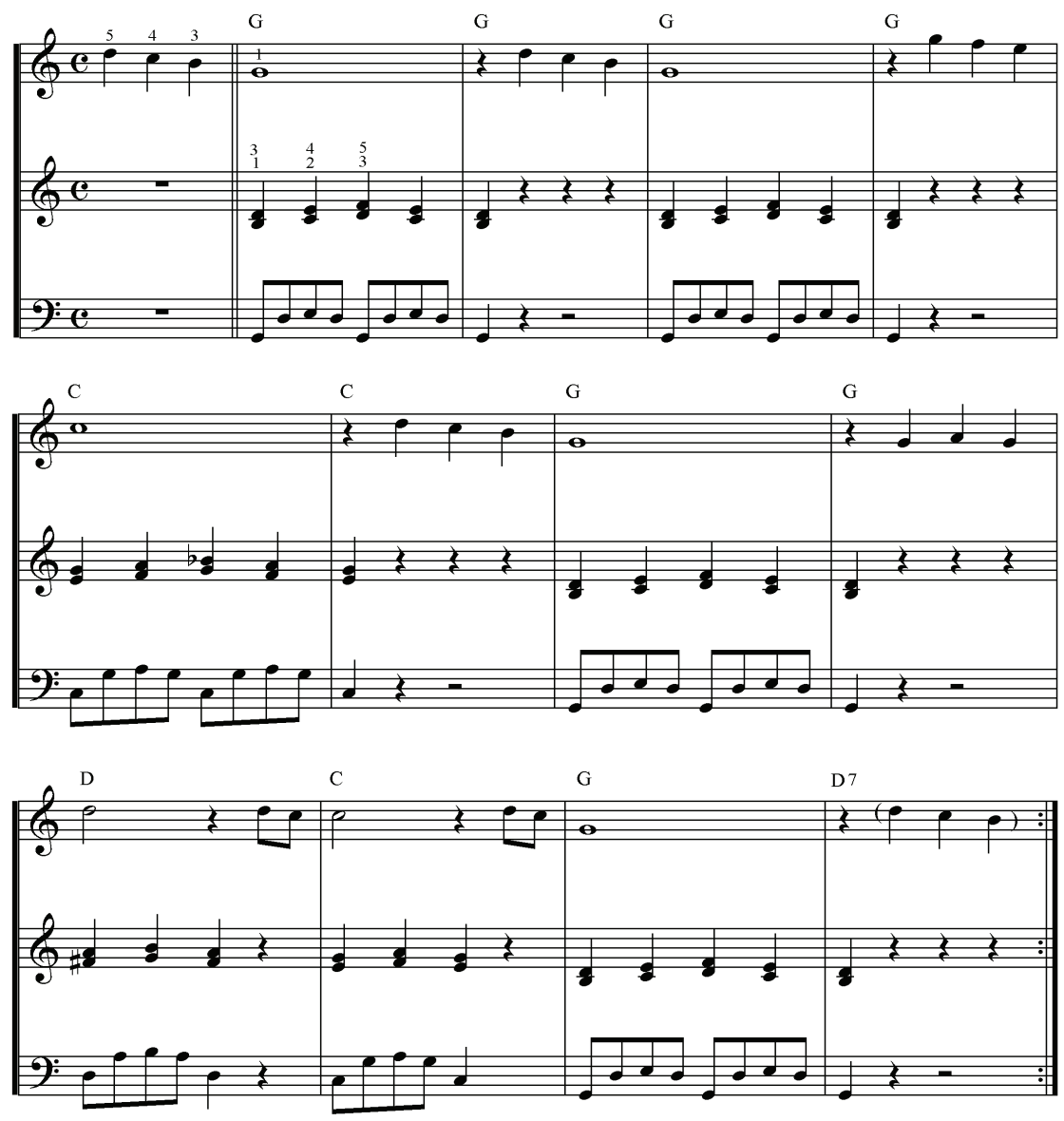

Figura 4: "Boogie blues" com três pentagramas. 
A partitura com três claves é uma boa opção para a prática no formato piano em grupo, pois podemos dividir os alunos em três grupos melodia, acordes (com mão direita e/ou esquerda) e baixo ostinato. $\bigcirc$ acompanhamento em terças na clave intermediária terá um desenvolvimento de uma nova harmonização a seguir (figura 6) e é uma boa alternativa para o estudo técnico de terças, com mudança de dedilhado alternado.

Ao sugerir o acorde inicial de Sól maior na primeira inversão (figura 3) antecipou a próxima etapa do exercício, que é de inserção de acordes na melodia com a mão direita, como mostra a figura 5. Essa técnica consiste em adicionar junto com a melodia pelo menos uma nota do acorde no tempo forte, geralmente o primeiro tempo do compasso. Nota-se que o acorde pode ser formado por uma tríade (compasso 1) ou somente uma terça (compasso 2), sendo que o baixo executa a tônica do acorde, facilitando sua execução:
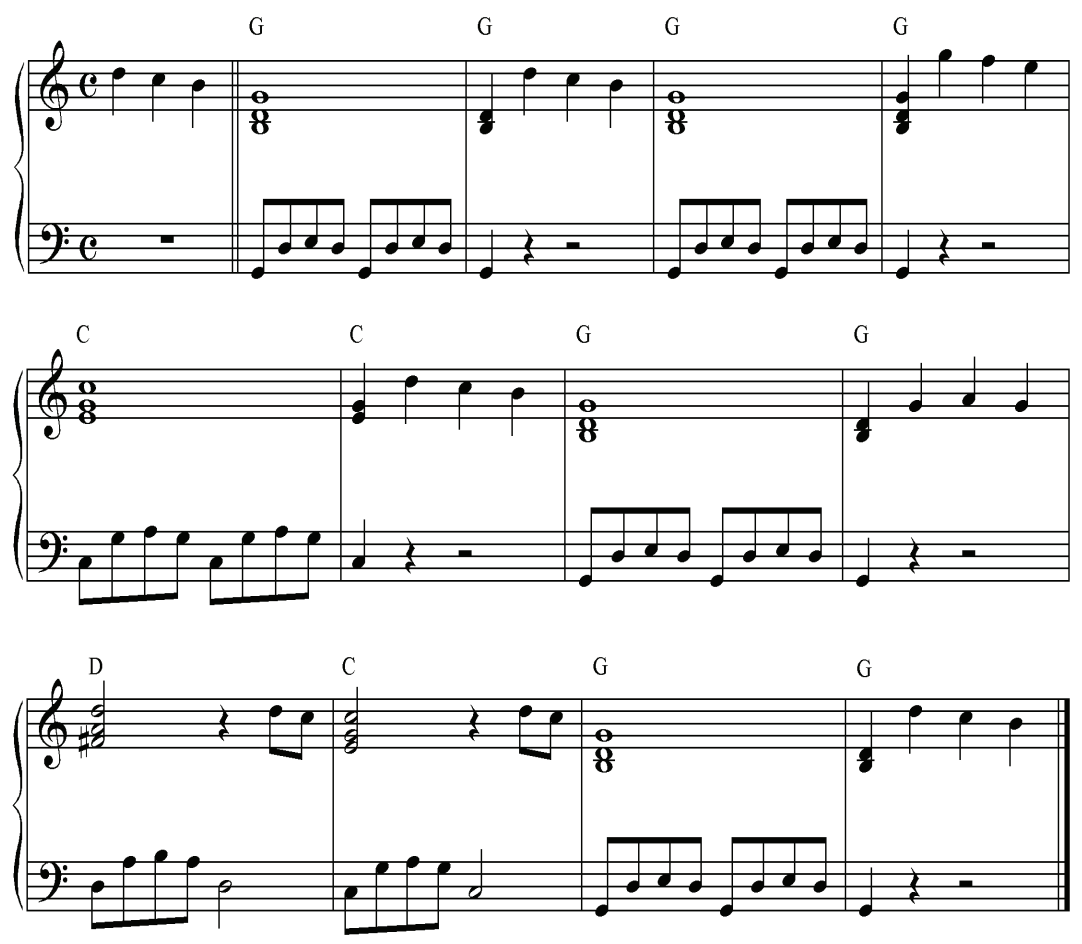

Figura 5: "Boogie blues" com acorde e melodia na mão direita. 
Pianisticamente este exercício é muito difícil para iniciantes, pois exige um deslocamento rápido do acorde no primeiro tempo para a nota do segundo tempo do compasso, assim como da última nota do compasso 2 para a montagem do acorde melódico do compasso 3. Por outro lado, nas nossas aulas de Piano Complementar há alunos de diversas experiências instrumentais, de modo que é saudável apresentar exercícios menos básicos do ponto de vista motor, mesmo que nem todos os alunos possam experimentar e praticar a atividade no momento, mas abre-se uma possibilidade de praticar no futuro, contemplando, assim, todo o grupo. Dessa maneira, todos os alunos puderam se engajar na atividade e efetivamente se beneficiar com o exercício.

Sobre esta técnica de harmonização na mão direita, Rogério Santos (2013) afirma:

A mão direita executa simultaneamente as notas da melodia e da harmonia. Trata-se de exercício bastante interessante, pois introduz o conceito de diferentes vozes executadas pela mesma mão, o que é fundamental para o desenvolvimento da polifonia em instrumentos de teclado. Aqui, o aluno necessita que o conhecimento de acordes esteja bem estabelecido para acrescer à melodia as notas relacionadas a cada harmonia. Como este tipo de exercício exige atenção total para a função da mão direita, a atividade da mão esquerda consiste apenas em tocar a nota fundamental do acorde (Santos, 2013, p. 185-186).

A próxima etapa de harmonização foi inserir o acompanhamento em terças (figura 4, pentagrama intermediário) em cada tempo na mão direita junto com a melodia, trazendo mais dificuldade e mais movimento à música, conforme mostra a figura abaixo: 

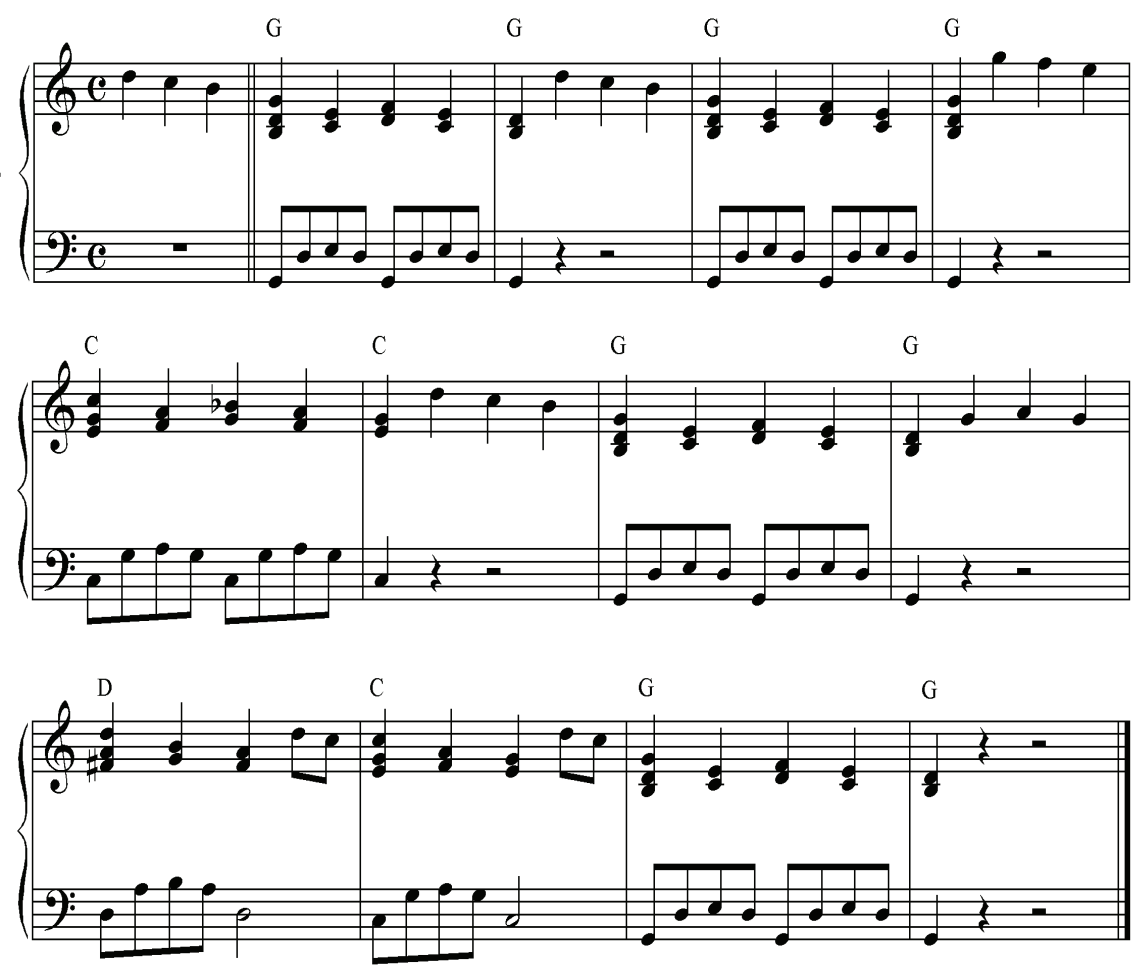

Figura 6: "Boogie blues", com melodia e acorde em cada tempo na mão direita.

A última etapa deste procedimento pedagógico consistiu em apresentar uma improvisação, um solo, uma melodia improvisada escrita na forma blues, podendo inclusive ser executada ao mesmo tempo da melodia, construindo, assim, um arranjo. Podemos observar no vídeo (2015) que um dos grupos executou "Boogie blues" três vezes, com tema, solo e a terceira vez executou tema e solo simultaneamente. Nessa atividade cada parte (pentagrama) foi executada por um grupo de alunos e a improvisação foi tocada somente pelos alunos que tinham mais habilidade motora. Com isso, esse blues foi transformado em uma peça para piano em grupo com 4 partes. 

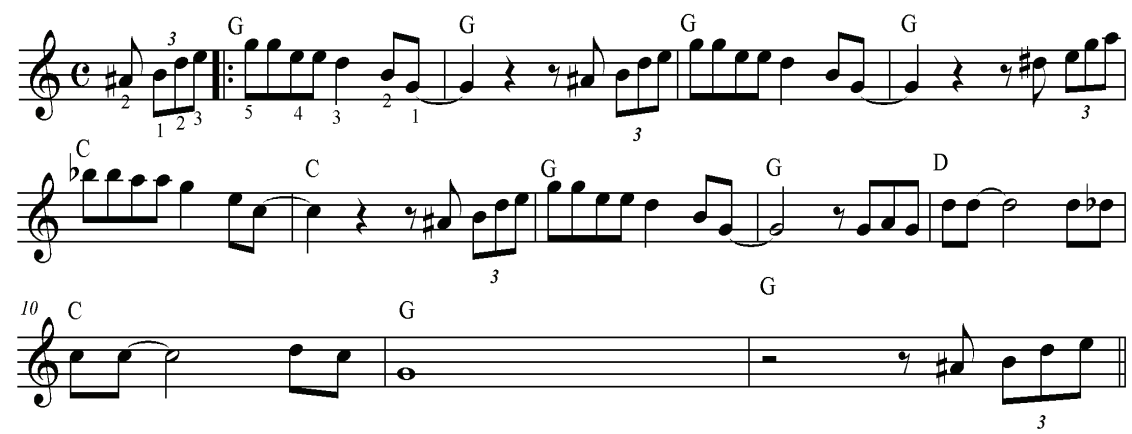

Figura 7: improvisação na forma Blues em Sol.

Naturalmente as etapas de aprendizagem aqui inseridas não foram dadas de uma só vez mas conseguimos expô-las em duas aulas de 50 minutos, Observou-se, porém, que houve grande interesse dos alunos em conhecer e manusear técnicas de estudo que contemplem a improvisação, a harmonização, o arranjo e o ritmo na forma blues. Temos, portanto, várias opções de harmonização para a mesma música, descritas abaixo:

1. Aprendizagem da melodia com a mão direita (MD);

2. Aprendizagem da melodia com a mão esquerda (ME);

3. Estudo da melodia (MD) + baixo escrito (ME) - figura I;

4. Acompanhamento em ostinato (ME) - figura 2;

5. Aprendizagem dos acordes encadeados a partir da fundamental, da la inversão (figura 3 ) e $2^{a}$ inversão;

6. Estudo da melodia (MD) + acompanhamento em ostinato (ME) figura 2;

7. Aprendizagem de acompanhamento em terças - figura 4; 
8. Estudo melodia + acordes (MD) e ostinato (ME) - figura 5;

9. Estudo melodia + acompanhamento em terças (MD) + ostinato (ME) - figura 6;

10. Improvisação - figura 7.

Utilizando a mesma obra, instruímos os alunos a apenas passarem de uma etapa a outra depois de automatizarem a anterior. Eles puderam também ouvir os colegas tocando as outras partes, de modo que essa troca tornou-se muito válida à medida em que os alunos conseguiram executar cada uma das partes aqui expostas trabalhando com mãos separadas ou juntas, criando cada vez mais independência de mãos e muitos deles conseguiram memorizar a peça.

\section{Resultados}

Para a análise e avaliação dos resultados, consideramos como instrumentos de coleta de dados os registros audiovisuais (disponivel em Vídeo Boogie Blues Piano em grupo, 2015), o questionário feito imediatamente após a atividade e um questionário posterior (após quatro meses da experiência) e para os dados recolhidos tivemos dois indicadores, o conhecimento do estilo (forma blues, a relação dos acordes, a execução de tercinas) e a movimentação ao piano (encadeamento de acordes, dedilhado, saltos). Para a nossa pesquisa trabalhamos com três grupos das disciplinas Piano em Grupo e Piano Complementar em duas instituições de nível superior e 48 alunos participaram dos questionários em dois dias de aula (200 minutos).

Após a atividade prática ao piano os alunos preencheram o questionário Boogie Blues e tivemos o seguinte resultado como parte dos dados analisados: 


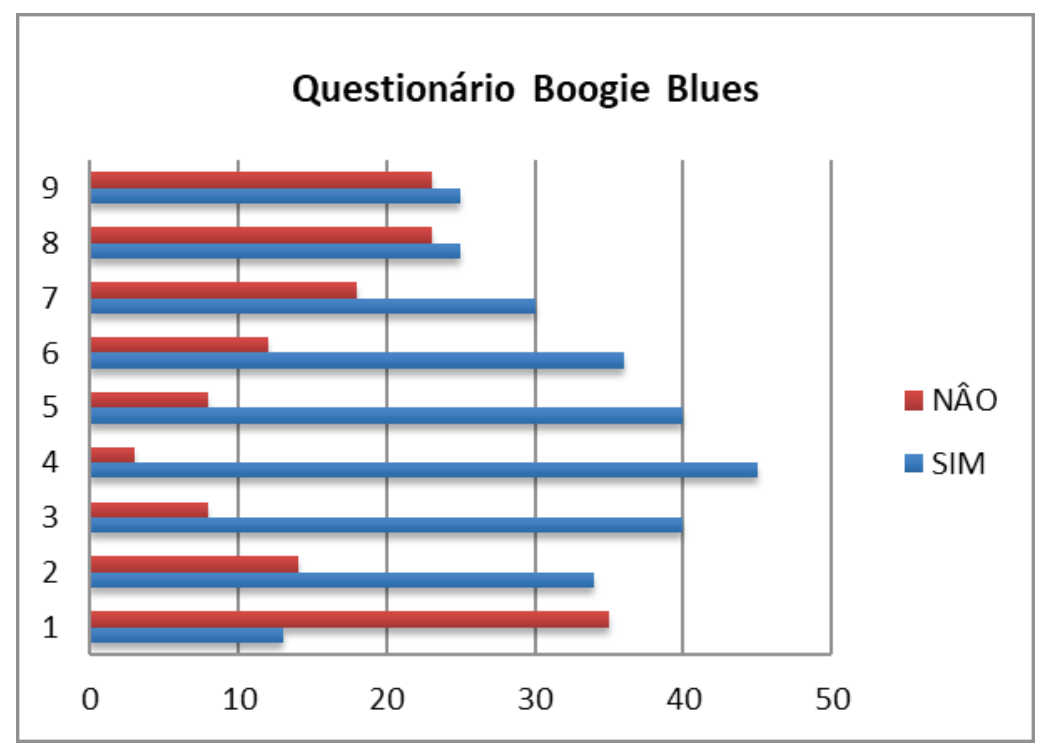

Figura 8: Gráfico Questionário Boogie blues.

Legenda:

1) Sobre a figura rítmica "duas colcheias" e a pulsação usada no jazz "tercina" de colcheia sendo a segunda ligada, você teve dificuldade de executar?

2) Já conhecia a forma blues?

3) Você conseguiu memorizar os acordes deste blues?

4) Foi capaz de executar o tema Boogie Blues com a mão direita?

5) Foi capaz de executar o baixo com a mão esquerda?

6) Foi capaz de executar o acorde (pentagrama 2) com a mão direita?

7) Foi capaz de executar o tema Boogie Blues com as duas mãos?

8) Foi capaz de executar o solo (improvisação) com a mão direita?

9) Teve alguma dificuldade ao fazer esta atividade? 
Sobre o indicador "Compreensão do estilo", questões l a 3 do questionário, apresentamos em aula a inserção histórica do blues na cultura estadunidense, a estrutura de doze compassos da forma blues em 12 compassos com sua sequência de acordes e em seguida fizemos uma leitura da partitura em que a relação dos acordes (tônica, subdominante, dominante) foi observada. Nesse ponto uma importante questão observada foi a característica rítmica que este blues possui, o dito swing do jazz, em que a leitura de duas colcheias executa-se uma tercina de colcheias, sendo a segunda ligada à primeira nota. A maioria dos alunos não sabia que a intenção rítmica era diferente da escrita e logo que executamos ao piano houve boa compreensão dos alunos, de modo que pudemos perceber o resultado nos vídeos filmados com essa atividade. $\bigcirc$ resultado do questionário mostrou que 70\% conheciam a forma blues, $83 \%$ conseguiram memorizar a forma e os acordes e 74\% tiveram dificuldade de executar a tercina de colcheia com a segunda nota ligada. Nos dois grupos da Faculdade Campo Limpo Paulista, a música foi também apresentada por diversos grupos na avaliação Seminários, momento em que os alunos se agrupam e escolhem duas músicas do repertório para apresentar aos colegas. $\bigcirc$ resultado foi muito positivo, pois a maioria dos alunos memorizou a música, alguns improvisaram sobre a harmonia do blues, criando várias versões de harmonização, e criaram diversos arranjos.

Sobre o indicador "Movimentação ao piano", dos 48 alunos entrevistados, $94 \%$ dos alunos executaram o tema "Boogie Blues" com a mão direita, 83\% executaram o baixo com mão esquerda, 75\% executaram o acorde com a mão direita, 62\% foram capazes de executar o tema com as duas mãos, 52\% executaram o solo (improvisação) com a mão direita e 52\% tiveram alguma dificuldade ao fazer a atividade, como execução com mãos simultâneas, memorização, harmonização e leitura à primeira vista. Na execução do tema, acorde e baixo, vários alunos conseguiram executar gradativamente, tocando somente com uma mão e depois tentando juntá-las. Para acrescentar notas, como as figuras 5 e 6, poucos alunos conseguiram executar a melodia harmonizada devido à dificuldade técnica, mas é importante frisar que desde o começo da dinâmica alguns alunos de nível mais avançado já tocavam com as mãos juntas e puderam mostrar aos colegas a harmonização proposta. Por sua vez, todos os alunos comentaram que o estudo ajudou a pensar na harmonia da música, na sequência de acordes, no baixo e na melodia. 
Os alunos com maior proficiência puderam concentrar em destacar a melodia tocando-a mais forte do que as outras notas do acorde enquanto tocavam ao mesmo tempo o acompanhamento. Esse foi considerado um desafio por esses alunos. Já os alunos com menos experiência desenvolveram tocar os saltos e destacar a melodia, com as mãos separadas. Destaca-se ainda que o grupo que teve menos teclados disponíveis pode desenvolver mais a parte cognitiva do processo, pois desenvolveram a percepção (melódica/harmônica/ rítmica) ao ouvir a atividade sendo executada pelos colegas enquanto esperavam sua vez de tocar.

Como trabalhamos com três grupos de alunos, tivemos a oportunidade de percorrer caminhos diferenciados a partir da experiência desenvolvida anteriormente, transformando a vivência posterior, conforme a pesquisa-ação. Por exemplo, no primeiro grupo os alunos escolheram os acordes para o acompanhamento livremente e os alunos tiveram dúvidas na execução, sendo que vários executaram os acordes na posição fundamental. Tentamos, então, promover a participação de todos "na busca de soluções aos seus problemas", como aponta Thiollent (1986, p. 75), apresentando no segundo grupo essa atividade com os acordes na pauta como a figura 3, e mostramos a importância de encontrar notas em comum entre eles para que houvesse menos movimentação da mão.

Ao apresentar o solo do blues (figura 7), na primeira experiência a partitura não tinha dedilhado e os alunos tiveram dificuldade de execução porque nosso objetivo era que os alunos pudessem ler e executar as tríades com os dedos 1-3-5. A partir da segunda classe, a partitura já continha dedilhado. Desse modo, pudemos planejar uma melhora da prática, agir para implantar a melhora planejada, monitorar e descrever os efeitos da ação e por fim avaliar os resultados da ação, conforme diagrama do ciclo básico da investigação-ação proposta por David Tripp (2005, p. 448).

Decorridos seis meses, contatamos os alunos com o objetivo de apurar se eles se lembravam da atividade e caso sim, se poderiam descrever essa lembrança. Dos 48 alunos que participaram do primeiro questionário, 35 retornaram, sendo que somente 1 1,5\% não conseguiram se recordar e 88,5\% se recordavam da atividade, descrevendo várias etapas como forma do blues, baixo ostinato, sequência dos acordes, 
sendo que vários alunos relataram que ainda conseguiam executar a música, depois de seis meses.

Como já dissemos, a intencionalidade de nossa pesquisa é reforçar a importância da prática harmônica em aulas coletivas de piano para que os alunos tenham consciência do que se executa e para tanto definimos como eixo orientador a nossa própria experiência como professores e pesquisadores, por meio da pesquisa-ação, Ao avaliar nossa prática pudemos fazer uma autorreflexão a fim de intervir, colaborar e modificar nossas ações, levando em consideração que nossa pesquisa une a teoria e prática, ocorre ao mesmo tempo em que se ensina, pois:

A prática é o ponto de partida. Dela emergem as questões, as necessidades e as possibilidades, ou seja, a prática esboça os caminhos a percorrer. [...]. Parte-se da prática para voltar a ela. Porém, na volta, não se encontra a mesma prática inicial, há uma nova qualidade na medida em que o movimento ação-reflexão-ação gera transformações, que permitem avançar em direção à melhor compreensão do fenômeno, relativizando o imediatamente perceptível (Esteban; Zaccur, 2002, p. 21 -22).

A pesquisa-ação é uma estratégia utilizada por professores e pesquisadores de modo que eles possam utilizar suas pesquisas para aprimorar seu ensino e procedimentos pedagógicos e, em decorrência, o aprendizado de seus alunos. David Tripp afirma que a "pesquisa-ação é uma forma de investigação-ação que utiliza técnicas de pesquisa consagradas para informar a ação que se decide tomar para melhorar a prática" (Tripp, 2005, p. 447). Para Cesar Albino e Sonia Albano de Lima (2009, p. 101), a pesquisa-ação, de certa maneira, integra pesquisa e ação, realidade social e pensamento científico, subjetividade e objetividade, dados quantitativos e qualitativos. A pedagoga Amélia Franco entende que a pesquisa-ação deve ocorrer sempre no ambiente natural da realidade a ser pesquisada e a metodologia deve permitir ajustes, bem como caminhar de acordo com as sínteses provisórias que vão se estabelecendo no grupo. $O$ pesquisador, por sua vez, deve estar habilitado continuadamente a agir, reagir, refletir, planejar, ressignificar, 
replanejar, de acordo comas necessidades coletivas que surgem durante o período em que a pesquisa ocorre (Franco, 2005, p. 491). Nesse sentido, Albino e Lima (2009, p. 93) pontuam que um projeto de pesquisa que adota a pesquisa-ação como modelo investigativo tem como pano de fundo a incerteza, a imprevisibilidade, o recomeço. Isso requer um pesquisador experiente, pois ela não poderá ser utilizada por pesquisadores que desconheçam o funcionamento, o sentido e a utilidade do objeto que está sendo investigado.

Inicialmente nossa pesquisa estava embasada na pesquisa qualitativa. Com a pesquisa em andamento, detectamos a necessidade de se processar a investigação em duas instituições de nível superior, dois pesquisadores e seus alunos, encontrando respaldo na pesquisaação, afinal, nesse método de análise, "é importante a negociação, a interação, o diálogo e a abstenção de um poder hierárquico por parte do pesquisador em relação aos colaboradores (Albino; Lima, 2009, p. 94).

\section{Considerações Finais}

Aprender a harmonizar ao piano envolvereconhecer espacialmente os padrões dos acordes e suas relações, um processo cognitivo. Além disso, desenvolver as formas dos acordes e a habilidade de mudar de um acorde para outro abrange destreza motora. Esse estudo demonstra que a aula em grupo proporcionou aos alunos de níveis diferentes desenvolverem ambos os processos supracitados em níveis variados. Notou-se que as diferenças, respeitadas pelos professores, oportunizaram motivação e desenvolvimento. Como resultado, pudemos observar que houve bom entendimento nos dois indicadores propostos, "Movimentação ao piano" e "Compreensão do estilo", envolvendo as questões motora e cognitiva, passados seis meses da atividade, os alunos ainda conseguiam se lembrar de vários aspectos da música e vários deles tocaram a música ao piano.

Harmonização é, de fato, uma ferramenta essencial na formação pianística para pianistas e não-pianistas que têm o piano como instrumento de apoio. Tem se discutido muito as especificidades do piano em grupo, porém pouco sobre material sobre o repertório e suas 
etapas de ensino-aprendizagem. Procuramos desenvolver atividades que envolvem o estudo da harmonia dentro da prática instrumental do piano aproximando teoria e prática, pois o músico, ao conhecer os caminhos harmônicos da música estudada, compreende e assimila de forma mais efetiva, sendo capaz de harmonizar, memorizar e transpor suas peças conscientemente.

Este artigo discutiu a harmonização nas aulas de Piano Complementar no formato piano em grupo, tendo, na maioria das vezes, o professor como mediador e regente do grupo e procurou divulgar o desenvolvimento de um material pedagógico, os resultados e as diversas etapas de execução, não somente do ponto de vista harmônico, mas também rítmico, levando em conta a diversidade de nível de ensinoaprendizagem dos alunos.

\section{Referências}

ALBINO, César; LIMA, Sonia R. A. A aplicabilidade da pesquisaação na educação musical. Revista Música Hodie, v. 9, n. 2. Goiânia, 2009, p. $91-104$.

ALMADA, Carlos. Harmonia funcional. Campinas: Editora da Unicamp, 2009.

BASTIEN, James W. How to Teach Piano Successfully. Park Ridge: General Words and Music Co., 1973.

COATS, Sylvia C. Thinking As You Play: Teaching Piano in Individual and Group Lessons. Bloomington: Indiana University Press, 2006.

COSTA, Carlos Henrique:; MACHADO, Simone Corete. Piano em grupo: livro didático para o ensino superior. Goiânia: Ed. da PUC Goiás, 2012.

COUTO, Ana C. N. Ações pedagógicas do professor de Piano Popular: um estudo de caso. Dissertação (Mestrado em Música). Universidade Federal de Minas Gerais. Belo Horizonte, 2008. 
ESTEBAN, Maria Tereza; ZACCUR, Edwiges (Orgs.). Professorapesquisadora: uma práxis em construção. Belo Horizonte: Autêntica, 2002. Press. 2010.

FISHER, Christopher. Learning piano in groups. Oxford University

FRANCO, Maria Amélia S. Pedagogia da Pesquisa-ação. Revista da FEUSP: Educação e Pesquisa. São Paulo, v. 3 I, n. 3, p. 483-502, set./ dez. 2005.

HILLEY, Martha; OLSON, Lynn F. Piano for the Developing Musician. 6. ed, Belmont CA: Wadsworth Publishing Company, 2001.

KAPLAN, J.A. Teoria da aprendizagem pianística. $2^{a}$ ed. Porto Alegre: Musas, 1987.

LANCASTER, E. L.; RENFROU, Kenon D. Alfred's Group Piano for Adults An Innovative Method Enhanced with Audio and MIDI Files for Practice and Performance. 2. ed. New York: Alfred Publishing Co., 1996.

LUCCA, Jussara D. $\bigcirc$ ensino do Piano Popular no curso de bacharelado em música popular da Faculdade de Artes do Paraná. Anais do XIV Encontro Anual da ABEM. Universidade Estadual de Minas Gerais. Belo Horizonte, 2005.

LYKE, J; YVONNE, E. Creative Piano Teaching. Illinois: Stipes Publishing Company, 1987.

MACHADO, Maria I. L. O piano complementar na formação acadêmica. Per Musi, Belo Horizonte, n. 27, 2013, p. 115-131.

MACHADO, Silmone C. A presença do piano em grupo em instituições de ensino superior no Brasil. Revista Orfeu, ano I, n. I. jan-jun 2016, p. 133-155.

MELO, Betania M. F. Uma atividade musical para adultos através do Piano: proposta de trabalho. Dissertação (Mestrado em Música). Universidade Estadual de Campinas. Campinas, 2002. 
MONTANDON, Maria Isabel. Aula de piano e ensino de música: análise da proposta de reavaliação da aula de piano e sua relação com as concepções pedagógicas de Pace, Verhaalen e Conçalves. Dissertação. Instituto de Artes, Universidade Federal do Rio Grande do Sul, 1992.

REINOSO, Ana Paula T. O Ensino de Piano em Grupo em Universidades Brasileiras. Dissertação (Mestrado em Música). Universidade Federal do Estado do Rio de Janeiro, Rio de Janeiro, 2012.

SANTIACO, Diana; FONSECA, Larissa P. R. Memória e aprendizado musical: a psicologia cognitiva na sala de aula. In: VIEIRA, L.B.; ROBATTO, L.. TOURINHO, C. (org.). Trânsito entre fronteiras na música. Belém: Ed. PPCARTES, 2013. (p. 115-144)

SANTOS, Rogério L. $\bigcirc$ ensino de piano em grupo: uma proposta para elaboração de método destinado ao curso de piano complementar nas universidades brasileiras. Tese (Doutorado em Música). Escola de Comunicações e Artes. Universidade de São Paulo, São Paulo, 2013.

SWANUICK, Keith. Ensino instrumental enquanto ensino de música. Trad. Fausto Borém. Cadernos de Estudos Educação musical. Escola de Música da UFMG, n. 4/5, p. 7-14, nov, 1994.

THIOLLENT, Michel. Metodologia da pesquisa-ação. São Paulo: Cortez, 1986.

TRIPP, David. Pesquisa-ação: uma introdução metodológica. Educação e pesquisa. São Paulo, v. 3 1, n. 3, set./dez. 2005, p. 443-466. Tradução de Lolio Lourenço de Oliveira.

Vídeo Boogie Blues Piano em Grupo. Disponivel em: https://www. youtube.com/watch? $v=42$ EArlwjbOM Acesso em 08/12/2015. 


\section{Sobre os autores}

Carlos Henrique Costa - é professor de regência, piano, e piano em grupo da Universidade Federal de Goiás, coordenador do Programa de Pós-graduação em Música da UFC e desenvolve pesquisa nas áreas de Piano em Grupo, performance do piano e música de câmara. Bacharel em Física pela Unicamp, bacharel em piano pela Universidade do Alabama em Huntsville, mestre em piano pela Universidade Estadual de Ohio, mestre em regência pela Universidade da Ceorgia em Athens e doutor em piano pela mesma universidade. Como pianista solista e camerista tem se apresentado nos Estados Unidos, Itália, Portugal e Brasil com instrumentistas como Carmelo de los Santos, Ana Flavia Frazão, Johnson Machado, Liliana Bizinechi entre outros. Regeu a Orquestra Sinfônica da Universidade da Ceorgia, a Orquestra Sinfônica da Universidade de Wyoming, a Orquestra Sinfônica de Goiânia e a Orquestra Acadêmica Jean Douliez da UFC. Em 2012 lançou o "Piano em Grupo: Livro Didático para Ensino Superior" e coordenou o II Encontro Internacional de Piano em Grupo.

Liliana Harb Bollos - Pianista e professora, atualmente desenvolve a pesquisa pós-doc em Harmonização no Piano em Grupo na EMAC-UFC. É doutora em Comunicação e Semiótica pela PUC-SP, mestre e bacharel em Música (performance em piano - jazz) pela Kunst Universität Graz (Áustria) e bacharel e licenciada em Letras (FFLCH-USP). É autora dos livros Bossa Nova e Crítica: Polifonia de Vozes na Imprensa (Annablume / Funarte, 20 10) (Prêmio Funarte de Produção Crítica em Música 2010) e Clara na Música Popular (Ed. Som, 2011 ). É integrante do Quarteto Sonoro (com Daniel Allain, Fernando Corrêa e Sérgio Schreiber), com o qual lançou o CD Sonoridades em 2015 e em 2017 lançou a caixa de 3 CDs com a cantora Tutti Bae. Como educadora, já lecionou no Conservatório de Tatuí, Faculdade de Música Carlos Gomes, EMESP e atualmente é professora da FACCAMP, onde também coordena o curso de Pós-graduação em Música Popular.

Recebido em 05/01/2017

Aprovado em 02/09/2017 